\title{
Study on the Application of HACCP System in Management of Postgraduate Course Teaching
}

\author{
Jun Yang a, Haibin Liu ${ }^{\text {b }}$, Meiqiong Su c, Qiaozhen Gu ${ }^{d}$, Ran Xu ${ }^{\mathrm{e}}$ \\ Graduate School, Northwest A\&F University, Shaanxi, 712100, China \\ ajunyang2012@nwsuaf.edu.cn, bhaibin553@nwsuaf.edu.cn, csumeiqiong@nwsuaf.edu.cn, \\ dguqiaozhen@nwsuaf.edu.cn, elilyxuran9998@163.com
}

\begin{abstract}
In this paper the fundamental principles of HACCP system were used to construct a monitoring and quality guarantee system in management of postgraduate course teaching by analyzing and confirming the hazards and critical control points in postgraduate course teaching in order to assure the quality of postgraduate course teaching.
\end{abstract}

Keywords: HACCP; Postgraduate; Course teaching; Quality control and monitoring system.

\section{HACCP质量管理体系在研究生课程教学管理中的应用探究}

\section{杨军, 刘海斌, 苏美琼, 古巧珍, 徐然}

西北农林科技大学研究生院, 杨凌 中国

摘 要: 本文借鉴HACCP质量管理体系原理, 对研究生课程教学全过程的质量影响因素进行分 析, 确定关键控制点, 探索构建研究生教学质量监控和保障体系, 保证研究生课程教学质量。

关键词: HACCP; 研究生; 课程教学; 质量监控体系

\section{1. 前言}

课程学习是我国学位和研究生教育制度的重要特征, 是保障研究生培养质量的必备环节, 在研究生成长成才中具有全面、综合和基础性作用 [1]。构建科学有效的课程教学质量监控和 保障体系, 是规范研究生课程教学秩序、提高研究生课程教学质量、发挥课程学习在研究生 培养中的作用的必要手段 [2]。HACCP质量管理体系是人们在食品生产过程中为保证食品生产 质量而总结出的科学、高效的生产管理方法, 对研究生课程教学质量监控与保障体系的构建 有一定的借鉴意义。

\section{HACCP体系简介}

\section{1. HACCP 体系基本原理}

HACCP是危害分析与关键控制点（Hazard Analysis Critical Control Point）的简称。 国家标准GB/T15091-1994《食品工业基本术语》对HACCP的定义为：生产 (加工) 安全食品的一 种控制手段; 对原料、关键生产工序及影响产品安全的人为因素进行分析, 确定加工过程中 的关键环节, 建立、完善监控程序和监控标准, 采取规范的纠正措施。HACCP是一个系统的 管理方法, 它覆盖了从原料到餐桌的整个食品生产加工过程, 并对生产加工过程的各种因素 进行连续系统的分析, 是人们在实践中总结出来的最有效的保障食品安全的管理办法 $[3,4]$ 。 2. 2. HACCP 体系的特点

HACCP是一种结构严谨的控制体系，与传统监督管理方法的最大区别是将预防和控制的重 点前移, 通过对食品原料和生产加工过程进行危害分析, 找出控制产品质量安全的关键环节, 并采取有效措施加以控制, 做到有的放矢、经济高效、防患于未然, 提高监督、检查的针对 性。 


\section{3. HACCP 体系的实施步骤}

建立HACCP体系通常包含以下12个步骤：（1）组建HACCP工作组；（2）描述产品;

确定产品的预期用途;（4）制作产品加工流程图; （5）现场确认流程图;（6）列出每个步 骤的所有潜在性危害，进行危害分析，并认定已有的控制措施；（7）确定关键控制点;（8） 建立每个关键控制点的关键限值; (9) 建立监控程序; （10）建立纠偏措施; (11) 建立验 证程序; (12) 建立文件和记录档案 [3]。

\section{3. 基于HACCP的研究生课程教学质量监控和保障体系分析}

在某种程度上，研究生课程教学活动的组织与实施和食品的生产加工过程具有相似性， 因此, 可以通过借鉴HACCP体系, 构建研究生课程教学质量监控和保证体系, 对在研究生课程 教学活动中容易出现的 “危害” 和关键点进行监控和预防, 从而充分发挥课程教学在研究生 培养中的重要作用, 提高研究生培养质量。

\section{1 组建研究生课程教学 HACCP 工作组}

与研究生课程教学相关的所有个人和组织都应参与构建研究生课程教学HACCP体系, 以确 保该体系系统、全面、科学、有效。研究生课程教学HACCP工作组成员应包括: (1) 课程教 学主体一一教师和学生; (2) 课程教学宏观管理和协调部门一一研究生院; (3) 课程教学 具体管理和实施部门一一开课学院; (4) 课程教学质量管理监控部门一一开课学院、研究生 院、学校研究生教育督导组、政府教育行政管理部门、社会第三方评价机构等。应当建立校 院两级的研究生课程教学HACCP工作组, 分别由研究生院和开课学院组建, 院级工作组在校级 工作组的指导和监督下开展工作。

\section{2 确定研究生课程教学目标}

研究生课程教学目标通过专业培养方案和课程教学大纲体现。课程教学目标应当体现对 研究生创新能力的培养。

3.3 构建研究生课程教学组织与实施流程图

研究生课程教学组织与实施流程如图1所示。

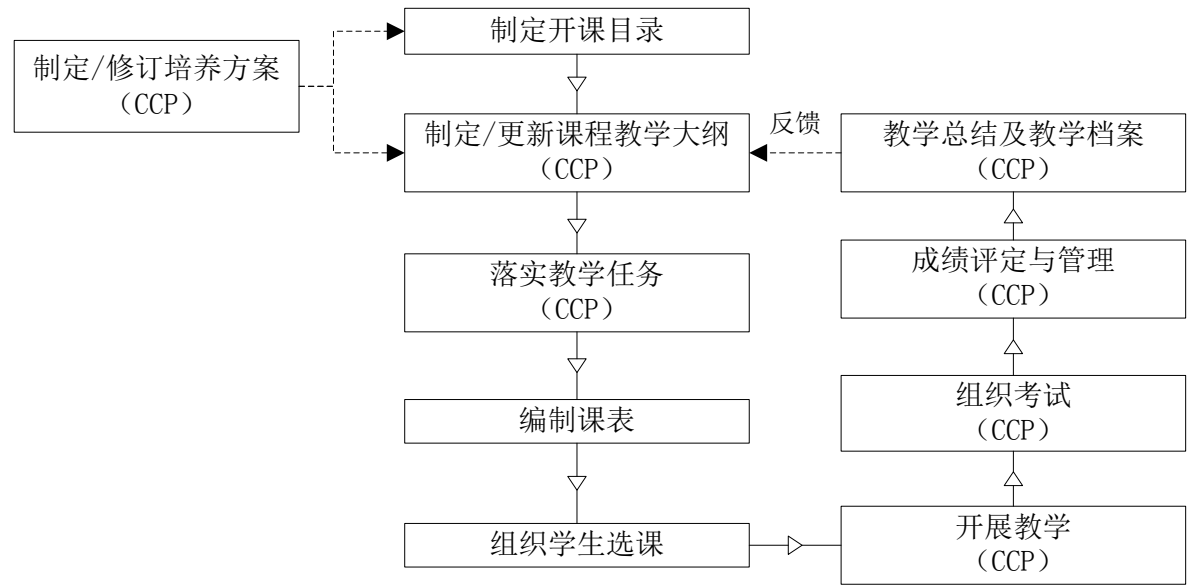

图1 研究生课程教学组织与实施流程图

\section{4 确定研究生课程教学质量关键控制点}

经过多年的研究生课程教学管理实践, 笔者认为研究生课程教学质量关键控制点主要包 括7个环节（如图1所示）。

\section{4. 1制定（修订）研究生专业培养方案}

专业培养方案主要回答 “为什么培养人, 培养什么人, 怎样培养” 的问题, 内容主要包 括培养目标、培养规格和素质要求、研究方向、学制、课程体系、实践环节、学分分配等。 专业培养方案是研究生培养目标与培养规格的具体化、实践化形式, 是实现专业培养目标和 培养规格的中心环节, 是研究生培养的纲领性文件和质量标准 [5,6]。 


\subsection{2制定 (更新) 课程教学大纲}

课程教学大纲是指导课程教学的纲领性文件, 规定了课程性质、教学目标、教学内容、 学时安排、教材及参考书等, 是培养方案的具体体现和落实, 是组织教学、制定授课计划、 编写教材以及教学质量检查的主要依据, 也是课程建设和课程评估的重要内容 [7]。

3.4 .3 落实教学任务

落实教学任务的本质是为计划开设的课程选择能够胜任课程教学工作的教师。具备良好 的知识储备和业务素质的教师是研究生课程教学质量的重要保障。

3. 4.4 开展教学工作

课程教学目标通过教学工作实现。规范的教学秩序是课程教学质量的基本保障。

\section{4.5. 组织考试}

考试是一种鉴定课程学习效果的方法, 必须保证考试的严肃性, 严格规范考试组织工作, 确保考试成绩真实、公平, 是保障课程教学质量的重要手段。研究生课程考试应实行多阶段、 多样化考核, 综合评定学生成绩, 充分发挥课程考试对学生课程学习的导向和约束作用。

3. 4. 6. 成绩评定与维护

课程成绩应当真实反映学生的学习水平。必须严格规范成绩评定和维护工作，从而保证 研究生课程教学和考试的严肃性。

3. 4. 7. 教学总结和教学档案管理

教学总结是教师在完成一门课程的全部教学任务后对教学经验进行总结, 用以提升自身 教学能力和水平, 提高授课质量。教学档案是教学检查的重要内容, 任课教师应当全面整理 教学档案并妥善保存。

\section{4. 基于HACCP体系的研究生课程教学质量监控与保障体系构建}

\section{1 建立研究生课程教学质量关键控制点的监控体系}

建立健全关键控制点的监控体系是保障研究生课程教学质量的关键。首先，要制定研究 生课程教学和学习管理规定, 使各种监控措施有法可依, 同时明确各主体的责任和义务, 实 现研究生课程教学质量问责制。其次, 组建校院两级研究生教育督导组, 制定督导工作条例, 切实发挥督导组对研究生课程教学的监督、评价和诊断功能。第三, 依据关键控制点建立研 究生课程质量监控与评价指标体系, 开课学院依据评价指标体系严格管理研究生课程质量关 键控制点, 督导组专家依据指标体系对开课学院及任课教师进行全程监控、量化评价, 对在 监控过程中发现的问题, 及时反映, 敦促解决。督导组专家在一定周期内发布研究生课程教 学质量监控和评价结果, 提出诊断意见, 督促开课学院和任课教师改进工作, 切实发挥教育 评价结果的激励与约束作用。第四, 提升研究生课程教学质量监控工作的信息化水平。利用 信息技术开展研究生课程教学质量监督工作, 不仅省时高效, 而且客观真实。要充分利用研 究生综合管理信息系统、研究生课程教学质量评价系统、多媒体教室控制系统、移动互联技 术等, 实现对研究生课程教学质量关键控制点的实时监控, 建立研究生课程教学督导网站, 做到监控信息实时在线, 实现全校、全员监督; 开通网上交流渠道, 收集教师和学生关于研 究生课程教学的意见和建议, 实现教师、学生与管理部门之间良性互动, 共同促进研究生课 程教学质量提升。

\section{2 建立研究生课程教学质量关键控制点的质量保障体系}

为参与课程教学管理、组织、实施、评价等的各个主体提供有效的支持与保障，是提高 研究生课程教学质量的必要手段。一是要充分发挥教师的积极性和创造性。学校设立教师发 展支持项目, 支持教师到国内外高校交流, 学习教育学相关知识, 了解最新的教学理念, 学 习新的教学方式和教学手段, 提高授课水平; 充分发挥教师教学发展中心职能, 为教师提升 教学能力提供全方位的支持, 实行教师教学能力培训与认证, 教师持证上岗; 设立研究生优 质课程 (示范性课程) 建设项目, 切实加强研究生课程建设; 设立研究生教学改革项目, 鼓 励教师积极探索课程教学规律, 总结教学经验, 凝炼教学艺术, 形成教学成果并用于教学实 
践; 建立完善的人事管理制度, 将教师教学工作量和教学绩效、教师教学能力水平、教师承 担优质课程建设项目和教学改革项目等纳入聘期考核、职称评定、招生名额分配以及津贴奖 励指标体系, 充分调动教师的积极性。二是充分调动研究生的课程学习积极性。学校将课程 学习成绩纳入研究生各类奖助学金评定基本要求, 引导研究生重视课程学习; 鼓励教师改进 教学方式, 采用翻转课堂等形式, 改善学生学习体验, 增强学生课程教学参与度。三是充分 发挥开课单位的积极性和创造性。学校为开课学院提供以绩效为导向的研究生课程教学经费 支持, 对在研究生课程教学工作中, 积极探索教学规律、加强课程建设、加强教师教学能力 建设、积极开展教学改革实践、改进教学管理与服务工作的学院加大经费支持和奖励力度。

4.3 转变管理部门职能, 实现研究生教学质量保障从外部控制向内在诉求转变。

学校研究生课程教学管理部门要 “简政放权”, 实行清单式绩效管理, 积极推进 “负面 清单” 管理, 更多采取事中、事后监管方式, 避免过多行政力量干预研究生教学活动, 尊重 基层教学单位和教师的主体地位, 充分调动其在研究生课程教学组织、管理与实施中的主动 性和创造性, 实现研究生课程教学质量建设标准和行动由 “一刀切” 向 “特色化” 转变; 学 校研究生课程教学管理部门要积极推进研究生课程教学由有形管理向无形服务转变, 综合运 用学校政策、制度、规定、财政拨款、标准、信息服务等手段, 引导和督促研究生课程教学 质量建设。要特别注意利用信息服务手段, 以中国科学技术大学为例, 该校紧密围绕提高研 究生教育质量和管理水平这一中心目标, 以满足新形势下导师、研究生和各级管理人员的需 求为导向, 以信息技术为手段, 贯穿研究生教育从招生、培养到毕业离校的各个环节, 打造 融信息服务、信息监控、信息公开、即时通讯为一体的研究生教育管理与服务平台, 从管理 理念、管理重心、管理方式和管理结构四个方面推动研究生教育管理模式由 “刚性” 向 “柔 性”、“结果” 向 “过程”、“金字塔型” 向 “扁平化”、“管理” 向 “服务” 转变 $[8]$, 为 高校研究生教育管理部门实现有形管理向无形服务转变提供了有益经验。总之, 要通过学校 研究生课程教学管理部门转变职能, 充分发挥教师和基层教学单位的积极性, 实现研究生课 程教学质量诉求由他律向自律转变 [9], 从而实现研究生课程教学质量监控与保障体系自觉、 高效运行。

\section{5. 结论}

本文将HACCP质量管理体系基本原理运用于研究生课程教学管理, 通过分析影响研究生课 程教学质量的各个因素、确定研究生课程教学质量关键控制点, 探索构建了研究生教学质量 监控和保障体系, 阐明了新形势下, 研究生课程教学管理部门转变职能、创新工作方式是实 现该体系自觉、高效运行的重要途径。

\section{References}

[1] Ministry of Education of the People's Republic of China. A guideline on Improving and Streng thening Graduate Curriculum Construction (2014，5th). http://www.moe.edu.cn/ publicfiles/ business/ htmlfiles/moe/s7065/201501/182992.html, 2014-12-05.

[2] Academic Degree Commission of the State council, Ministry of Education of the People's Rep ublic of China. A guideline on Strengthening the Construction of Quality Assurance and Super vision System of Academic Degrees and Graduate Education (2014, 3rd). http://www.moe. edu. cn/publicfiles/business/htmlfiles/moe/s7065/201403/165554.html, 2014-01-29.

[3] Bao Dayue. HACCP Implement Guide for Food Industries. Beijing: Chemical Industry Press, 2007: 1-3.

[4] Qian He. HACCP: Principles and Implementation. Beijin: China Light Industry Press, 2008: 6-7.

[5] Zeng Dongmei, Xi Hongjian, Huang Guoxun. On the Establishment of Professional Personnel Cultivation Project [J]. Research On Education Tsinghua University, 2002(5): 98-101. 
[6] Li Ali, Lu Xiangyang, He Jianhua et al. An Elementary Discussion to the Principles and Methods for Optimizing Postgraduate Cultivation Program [J].Journal of Hunan Agricultural University (Social Science), 2005, 6(2):67-69.

[7] Wei Ze. Study on the Problems in the Syllabus Development of Undergraduate Curriculum in Higher Education Institutions and Countermeasures [J]. Journal of Guangzhou Radio \& TV University, 2010, 10(1): 63-65.

[8] Academic Affairs Office, University of Science and Technology of China. Five Second Prizes of the National Teaching Achievement Award for Higher Education in 2014 [EB/OL]. http://oldteach.cmet.ustc.edu.cn/jxjb/jxjb567.htm, 2014-09-24.

[9] Zhang Jing, Wan Ming, Zhang Shulin, Pei Xu. Construct the Atmosphere of Quality Culture and Improve the Management Level of Graduate Education [J]. Academic Degrees \& Graduate Education, 2014, (3):48-52. 